\begin{tabular}{|c|c|}
\hline Title & Current Stability in Multi-Mesa Channel AIGaN/GaN HEMTs \\
\hline Author(s) & Ohi, Kota; A subar, Joel Tacla; Nishiguchi, Kenya; Hashizume, Tamotsu \\
\hline Citation & $\begin{array}{l}\text { IEEE Transactions on Electron Devices, 60(10), 2997-3004 } \\
\text { https://doi.org/10.1109// ED.2013.2266663 }\end{array}$ \\
\hline Issue Date & $2013-10$ \\
\hline Doc URL & http://hdl.handle.net/2115/53666 \\
\hline Rights & $\begin{array}{l}\text { (c) } 2013 \text { IEEE. Personal use of this material is permitted. Permission from IEEE must be obtained for all other uses, in } \\
\text { any current or future media, including reprinting/republishing this material for advertising or promotional purposes, } \\
\text { creating new collective works, for resale or redistribution to servers or lists, or reuse of any copyrighted component of } \\
\text { this work in other works. }\end{array}$ \\
\hline Type & article (author version) \\
\hline File Information & Ohi_et_al_IEEE_TED.pdf \\
\hline
\end{tabular}

Instructions for use 


\title{
Current Stability in Multi-Mesa-Channel AlGaN/GaN HEMTs
}

\author{
Kota Ohi, Joel T. Asubar, Kenya Nishiguchi, and Tamotsu Hashizume
}

(Invited Paper)

\begin{abstract}
We have developed and characterized multi-mesa-channel (MMC) AlGaN/GaN high-electron-mobility transistors (HEMTs), in which a periodic trench structure is fabricated only under the gate electrode. A surrounding-field effect in the MMC structure resulted in a shallower threshold voltage and a smaller subthreshold slope than those of the standard planar-type HEMT. In addition, the MMC HEMT showed a low knee voltage and a weak dependence of on-resistance $\left(\mathbf{R}_{\mathrm{ON}}\right)$ on the gate-drain distance. Following identical off-state bias stress, the MMC HEMT exhibited low current collapse. The relative decrease in access resistance of the MMC device compared to the planar device can reduce the effects of access resistance on the drain current. It is likely that a high impedance of each nano-channel also contributes to current stability of the MMC HEMT.
\end{abstract}

Index Terms-Access resistance, current collapse, GaN, HEMT, multi-mesa channel, off-state stress, subthreshold slope, threshold voltage.

\section{INTRODUCTION}

$\mathrm{G}$ aN-based heterostructure transistors are considered to be a J prime candidate for post-Si next-generation power applications because of material advantages, such as high breakdown electric field, high saturation electron velocity, and high carrier density at the heterointerface. Indeed, some groups have reported $\mathrm{AlGaN} / \mathrm{GaN}$ and $\mathrm{InAlN} / \mathrm{GaN}$ high electron mobility transistors (HEMTs) with excellent device performances such as high blocking voltages and low on-state resistances, which are very attractive for high-efficiency power-switching applications [1-11]. In addition, $\mathrm{AlGaN} / \mathrm{GaN}$ HEMTs have been demonstrated to operate with good switching characteristics and high power conversion efficiencies when used in DC/DC converters and DC/AC inverters [7, 12-14].

However, the widespread implementation of GaN-based transistors is still restricted by reliability issues [15-18], particularly by the well-known current collapse phenomenon.

This paragraph of the first footnote will contain the date on which you submitted your paper for review. It will also contain support information, including sponsor and financial support acknowledgment. For example, "This work was supported in part by the U.S. Department of Commerce under Grant BS123456".

The authors are with Research Center for Integrated Quantum Electronics, Hokkaido University, Sapporo 060-0814, Japan and CREST, Japan Science and Technology Agency (JST), Tokyo 102-0075, Japan (e-mail: hashi@ rciqe.hokudai.ac.jp).
Current collapse is the temporary reduction of the drain current following the application of high voltage and/or high power at both on- and off-state operations [19-22]. Field-plate structures have been applied to AlGaN/GaN HEMTs [23-27] to mitigate the concentration of electric field at the gate edge of the drain side, which is effective in reducing the current collapse. However, several reliability issues still remain in GaN HEMTs. To further improve the performance and operation stability of devices utilizing $\mathrm{AlGaN} / \mathrm{GaN}$ structures, it is important to design a suitable device structure with a successful surface passivation scheme.

We have developed a multi-mesa-channel (MMC) AlGaN/GaN HEMT schematically shown in Fig. 1 [28]. By forming a periodic trench, the MMC HEMT has parallel mesa-shaped channels with two-dimensional electron gas (2DEG) surrounded by the gate electrode. The device showed good gate controllability due to a lateral field effect that shifts the threshold voltage toward the positive bias direction. The threshold voltage shift can be increased by reducing the top width of the mesa channel. In addition, we have found that the MMC structure demonstrates lower off-state-stress-induced current collapse [29]. Very recently, similar device structures were reported by Liu et al. [30] and Lu et al. [31]. They demonstrated a similar $\mathrm{V}_{\mathrm{TH}}$ shift and good normally-off operation in nano-channel array AlGaN/GaN HEMTs [30] and tri-gate $\mathrm{GaN}$ metal-insulator-semiconductor field-effect transistors [31], respectively.

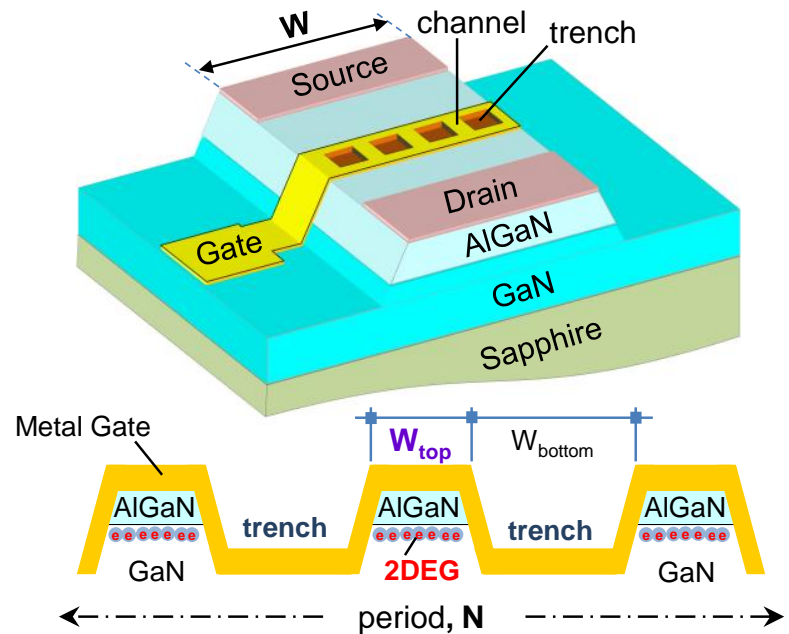

Fig. 1. Schematic illustration of the multi-mesa-channel (MMC) HEMT showing the periodic trench structure under the gate electrode. $\mathrm{W}_{\text {top }}$ is the width of the mesa channel. 
In the present study, we further investigated gate controllability and current stability of the MMC HEMT, focusing on their subthreshold characteristics, drain current dependence on the gate-drain spacing and current collapse behavior, in comparison with those of the conventional planar HEMT.

\section{DEVICE STRUCTURE AND FABRICATION}

We used an $\mathrm{Al}_{0.25} \mathrm{Ga}_{0.75} \mathrm{~N} / \mathrm{GaN}$ hetero structure grown on a (0001) sapphire substrate by metal organic chemical vapor deposition. The thickness of the AlGaN layer is $30 \mathrm{~nm}$. Typical values of concentration and mobility of the 2-dimensional electron gas (2DEG) are $9.0 \times 10^{12} \mathrm{~cm}^{-2}$ and $1330 \mathrm{~cm}^{2} / \mathrm{Vs}$, respectively, at room temperature (RT).

The fabrication process started with the formation of a $\mathrm{SiO}_{2}$ mask pattern on the $\mathrm{AlGaN} / \mathrm{GaN}$ structure by electron beam lithography and wet etching. Then, we carried out reactive ion-beam etching of the patterned sample to form a periodic trench, assisted by electron-cyclotron-resonance plasma using a gas mixture of $\mathrm{CH}_{4} / \mathrm{H}_{2} / \mathrm{Ar} / \mathrm{N}_{2}$. To completely eliminate the 2DEG in the trench region and to minimize plasma damage, etching depth was set to 50 to $70 \mathrm{~nm}$. Figure 2 (a) shows an AFM image of the AlGaN surface after the trench formation. A periodic trench structure was successfully fabricated, resulting in the formation of multi nano-channels with a width ranging from 50 to $200 \mathrm{~nm}$. Figure 2 (b) shows a typical AFM line profile along the mesa-trench structure, which in this case

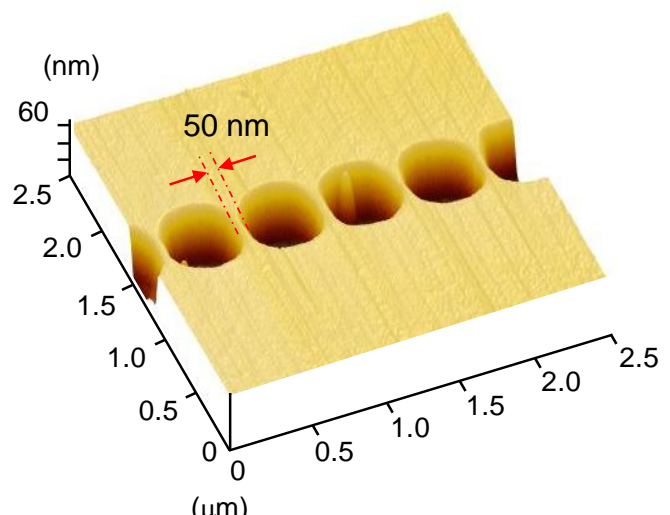

(a)

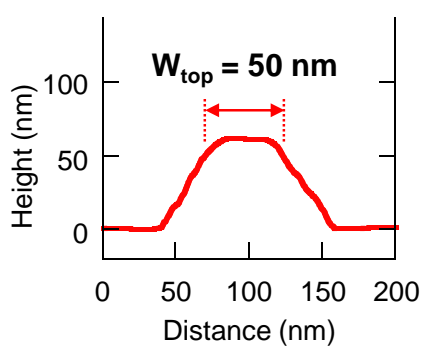

(b)

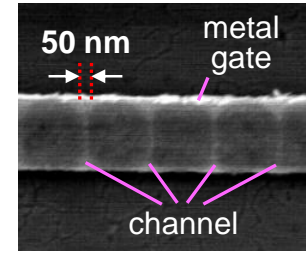

(c)
Fig. 2. (a) Bird's eye view AFM image of the AlGaN surface after the formation of the mesa-trench structure. (b) AFM line profile along the mesa-trench structure revealed an etching depth of approximately $60 \mathrm{~nm}$ and $\mathrm{W}_{\text {top }}$ of about $50 \mathrm{~nm}$. (c) SEM plan view image of the mesa-trench structure. revealed an etching depth of approximately $60 \mathrm{~nm}$ and $\mathrm{W}_{\text {top }}$ of about $50 \mathrm{~nm}$. After the dry etching, the $\mathrm{SiO}_{2}$ mask pattern was removed in a buffered $\mathrm{HF}$ solution, and a $\mathrm{Ti} / \mathrm{Al} / \mathrm{Ti} / \mathrm{Au}$ multilayer was deposited and annealed at $800{ }^{\circ} \mathrm{C}$ for $1 \mathrm{~min}$ to form source and drain ohmic contacts. The gate electrode was then defined by electron beam lithography and fabricated using $\mathrm{Ni} / \mathrm{Au}$. For the MMC HEMT, the gate electrode covered the periodic-trench region, as shown in the SEM image given in Fig. 2(c). Finally, for surface passivation, a 20-nm-thick $\mathrm{Al}_{2} \mathrm{O}_{3}$ film was deposited on the AlGaN surface by atomic layer deposition (ALD) system (SUGA-SAL100H) at $350{ }^{\circ} \mathrm{C}[32,33]$. In the ALD process, water vapor and trimethylaluminium were introduced into an ALD reactor in alternate pulse forms. The deposition rate of $\mathrm{Al}_{2} \mathrm{O}_{3}$ was $0.11 \mathrm{~nm} /$ cycle. All the fabricated devices have a gate length, $\mathrm{L}_{\mathrm{G}}$, of $0.5 \mu \mathrm{m}$ and a gate-source distance, $\mathrm{L}_{\mathrm{SG}}$, of $1 \mu \mathrm{m}$. The gate-drain spacing, $\mathrm{L}_{\mathrm{GD}}$, ranged from 1 to $20 \mu \mathrm{m}$.

\section{RESULTS AND DISCUSSION}

\section{A. $V_{T H}$ control and subthreshold characteristics}

Typical drain current-voltage $\left(\mathrm{I}_{\mathrm{DS}}-\mathrm{V}_{\mathrm{DS}}\right)$ characteristics of planar and MMC HEMTs with $\mathrm{L}_{\mathrm{G}}=0.5 \mu \mathrm{m}$ and $\mathrm{L}_{\mathrm{GD}}=10 \mu \mathrm{m}$ are shown in Fig. 3. The MMC HEMT in this figure has a mesa-top width $\mathrm{W}_{\text {top }}$ of $70 \mathrm{~nm}$ and 250 periods of mesa/trench structures within a gate-electrode width $\mathrm{W}$ of $100 \mu \mathrm{m}$. Thus, the effective gate width, i.e., the sum of $\mathrm{W}_{\text {top }}$ values, was $17.5 \mu \mathrm{m}$
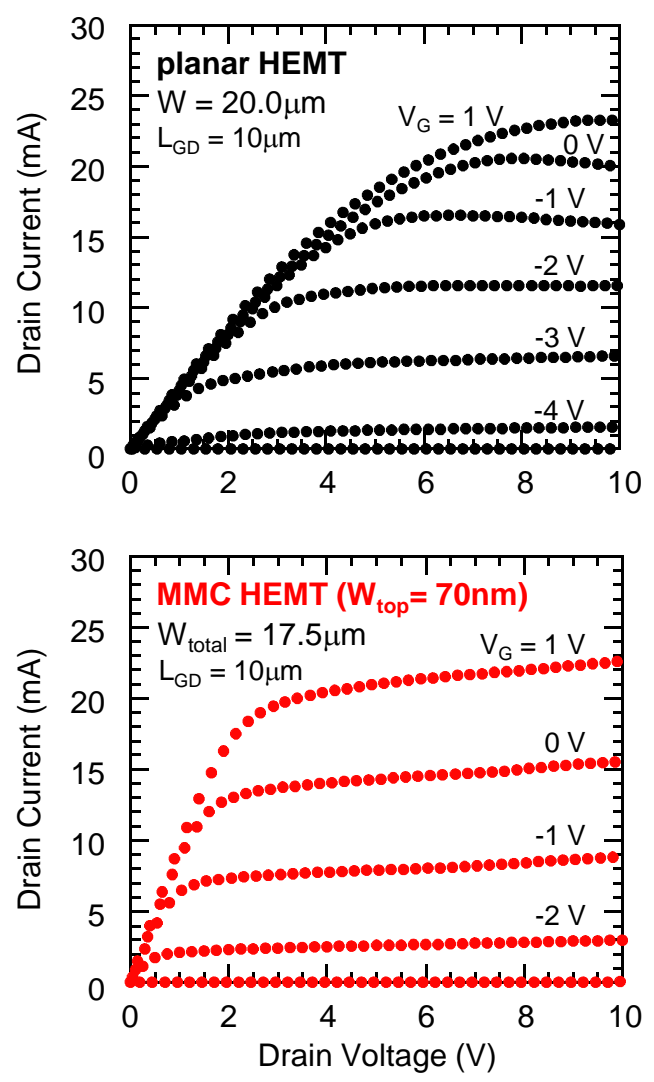

Fig. 3. Comparison of drain current-voltage $\left(\mathrm{I}_{\mathrm{DS}}-\mathrm{V}_{\mathrm{DS}}\right)$ characteristics of a planar HEMT and an MMC HEMT. At the same gate voltage $\mathrm{V}_{\mathrm{G}}$ of $1 \mathrm{~V}$, the MMC HEMT showed a lower knee voltage compared with the standard planar HEMT. 


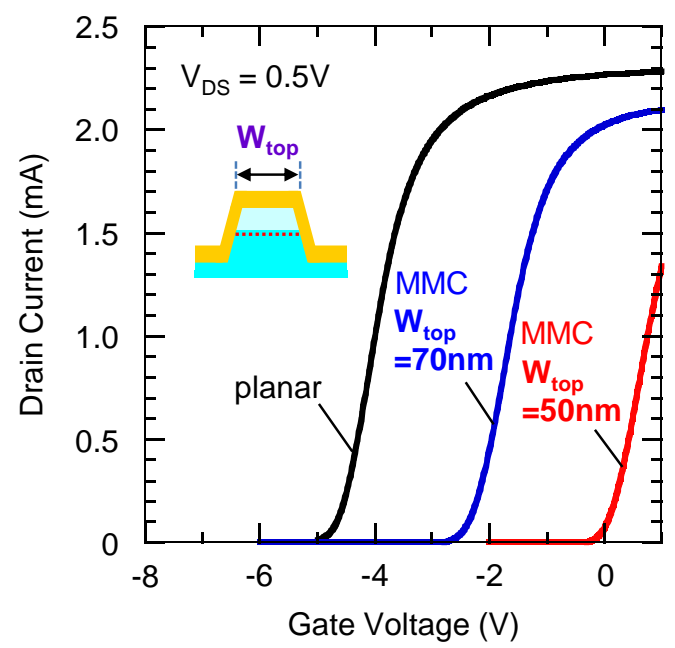

Fig. 4. Transfer characteristics in the linear region $\left(\mathrm{V}_{\mathrm{DS}}=0.5 \mathrm{~V}\right)$ of $\mathrm{MMC}$ HEMTs compared with that of a planar HEMT. For the MMC HEMTs, decreasing the channel width $\mathrm{W}_{\text {top }}$ (illustrated on the inset), shifted the threshold voltage toward the positive gate bias direction.

for the MMC structure. The MMC HEMT demonstrated good $\mathrm{I}-\mathrm{V}$ behavior, particularly showing a lower knee voltage than the conventional planar HEMT.

We also measured the breakdown characteristics of the planar and MMC HEMTs with $\mathrm{L}_{\mathrm{GD}}=10 \mu \mathrm{m}$ under off-state condition [28]. Both devices exhibited a breakdown voltage of about $250 \mathrm{~V}$, which is similar to reported data for the AlGaN/GaN HEMTs without field-plate technology [34]. The results obtained indicate that the periodic trench structure under the gate electrode does not lead to significant degradation of $\mathrm{AlGaN} / \mathrm{GaN}$ HEMTs breakdown characteristics.

To investigate the gate controllability of the MMC device, we measured the transfer and the subthreshold characteristics. Figure 4 shows the transfer characteristics of the planar and MMC HEMTs in the linear region $\left(\mathrm{V}_{\mathrm{DS}}=0.5 \mathrm{~V}\right)$. For the MMC device having $50 \mathrm{~nm} \mathrm{~W}_{\text {top }}$, there are 263 periods of mesa/trench structures within a gate electrode width of $100 \mu \mathrm{m}$, resulting in an effective gate width of $13 \mu \mathrm{m}$. As the mesa-top width was decreased, a systematic shift of the threshold voltage $\left(\mathrm{V}_{\mathrm{TH}}\right)$ toward the positive voltage direction was observed in MMC HEMTs. In particular, the MMC HEMT with $\mathrm{W}_{\text {top }}=50 \mathrm{~nm}$ showed a $\mathrm{V}_{\mathrm{TH}}$ nearly equal to $0 \mathrm{~V}$. Liu et al. [30] and Lu et al. [31] reported a similar $\mathrm{V}_{\mathrm{TH}}$ shift and good normally-off operation in nano-channel array AlGaN/GaN HEMTs and tri-gate GaN metal-insulator-semiconductor field-effect transistors, respectively.

Figure 5(a) shows the comparison of the subthreshold characteristics in the linear region at a drain voltage of $0.2 \mathrm{~V}$. The gate leakage currents are also plotted by broken lines. Low gate leakage currents were observed for the MMC HEMTs at reverse bias. However, the MMC device showed initially higher leakage currents than that of the planar device at around $\mathrm{V}_{\mathrm{G}}=0 \mathrm{~V}$. The gate contact of the MMC device includes Schottky interfaces with the AlGaN surface, the 2DEG edge and the dry-etched $\mathrm{GaN}$ surface, indicating that the leakage mechanism is rather complicated for the MMC device. In

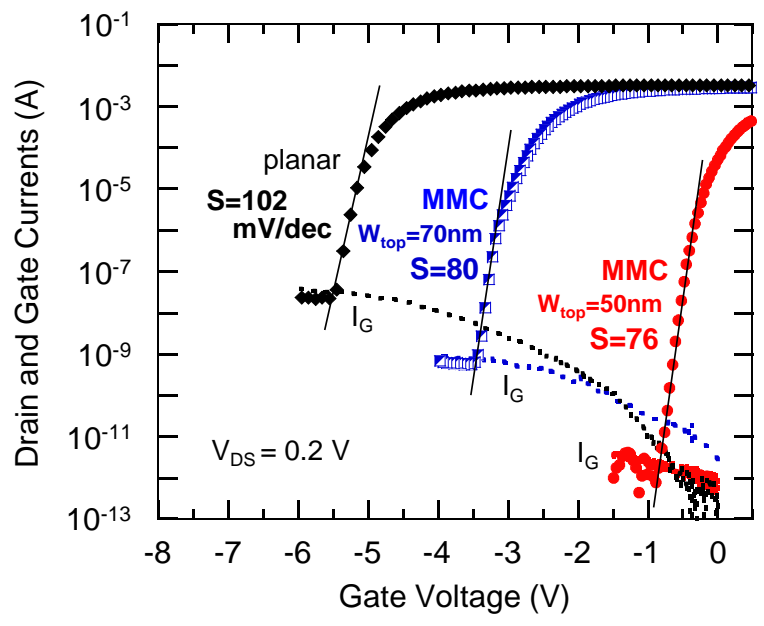

(a)

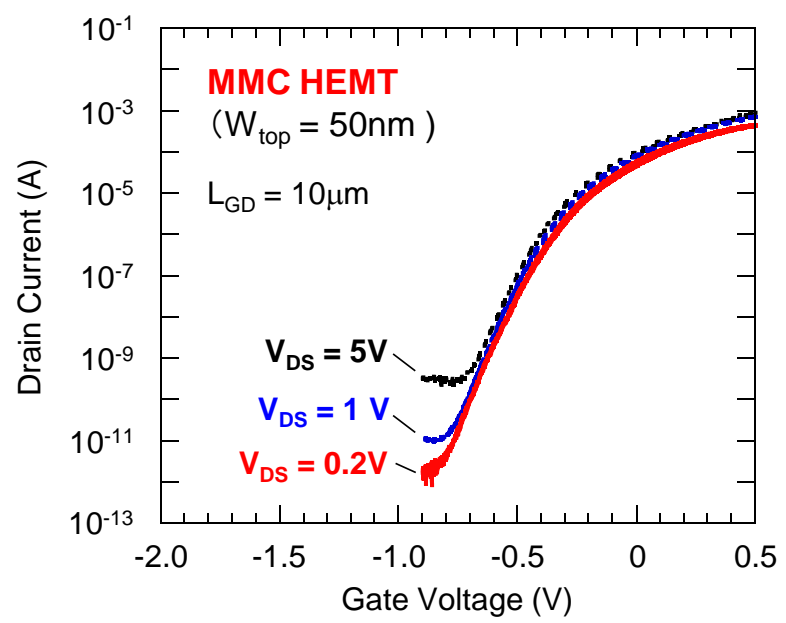

(b)

Fig. 5. (a) Subthreshold characteristics in the linear region $\left(V_{D S}=0.2 \mathrm{~V}\right)$ of the MMC HEMTs compared with that of the planar HEMT. (b) Subthreshold characteristics as a function of $\mathrm{V}_{\mathrm{DS}}$ for the MMC HEMT with $\mathrm{W}_{\text {top }}=50 \mathrm{~nm}$.

addition, it was found from calculations that for the MMC devices, the potential modulation through the mesa side-walls and undoped $\mathrm{GaN}$ layer becomes marked at reverse bias. It is likely that such potential distribution different from that of the planar HEMT is responsible for the difference in leakage behavior. As the gate structure of the MMC device includes metal/2DEG interfaces, we were expecting serious leakage through such interfaces. However, the result shown in Fig. 5(a) indicated that the metal/2DEG interface at the side wall does not cause severe leakage current. Lu et al. [31] also reported relatively low gate leakage currents for a similar device structure. In the MMC HEMTs, improvement of the subthreshold slope was observed with narrowing of the mesa-top width. In particular, the MMC HEMT with $\mathrm{W}_{\text {top }}=50$ $\mathrm{nm}$ showed a subthreshold slope of $76 \mathrm{mV} / \mathrm{dec}$ and a drain-current on/off ratio of $10^{8}$. Figure 5(b) shows the subthreshold drain currents of the MMC HEMT as a function of drain voltage. The subthreshold slope remained almost unchanged at different values of $\mathrm{V}_{\mathrm{DS}}$, indicating that the MMC 


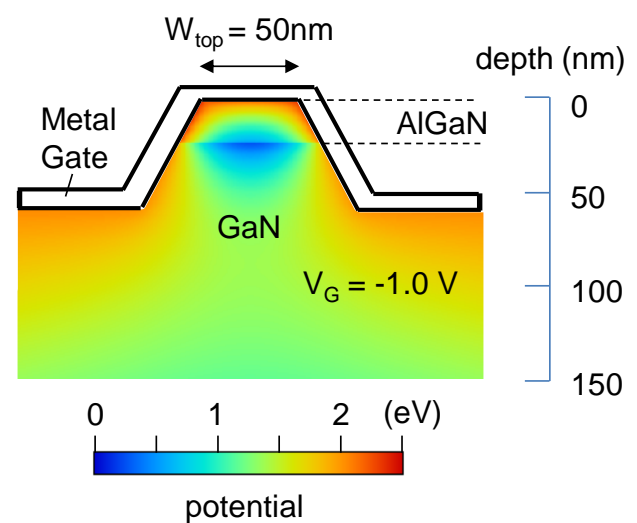

(a)

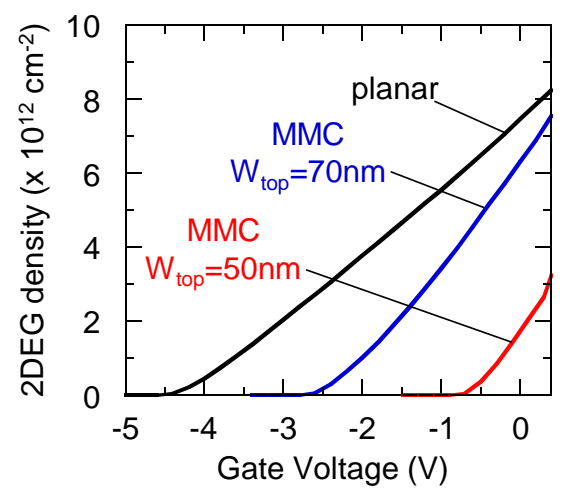

(b)

Fig. 6. (a) $2 \mathrm{D}$ potential distribution in MMC structure with $\mathrm{W}_{\text {top }}$ of $50 \mathrm{~nm}$. The gate and drain voltages were set to $-1.0 \mathrm{~V}$ and $0 \mathrm{~V}$, respectively. (b) Simulated 2DEG density as a function of gate voltage for a planar and MMC HEMTs showing better gate controllability of the 2DEG with decreasing $\mathrm{W}_{\text {top. }}$.

structure mitigates the drain-induced electric field effect on the gate controllability of the drain current.

We also calculated the 2D potential distribution around the channel region for the MMC structure with $\mathrm{W}_{\text {top }}=50 \mathrm{~nm}$ to gain more understanding of the surrounding-field effect. The gate bias was set to $-1 \mathrm{~V}$, which is near the threshold voltage, and the drain bias was set to $0 \mathrm{~V}$. The calculation result is shown in Fig. 6(a). The mesa-sidewall gate has a lateral field effect on the edges of the 2DEG. Moreover, as the width of the top gate decreases, the potential modulation through the undoped $\mathrm{GaN}$ layer becomes stronger, resulting in a field surrounding the 2DEG. This leads to a more effective gate control of the 2DEG density, as shown in Fig. 6(b), resulting to shallower $\mathrm{V}_{\mathrm{TH}}$ and good subthreshold characteristics for the mesa-gate HEMT with smaller channel width.

\section{B. Improvement of current stability}

As shown in Fig. 3, a small knee voltage $\left(\mathrm{V}_{\text {knee }}\right)$ is one of the characteristic features of the MMC HEMT. We thus investigated the $\mathrm{L}_{\mathrm{GD}}$ dependence of the drain $\mathrm{I}-\mathrm{V}$ characteristics of the planar and the MMC HEMTs. The drain I-V curves of both devices at $\mathrm{V}_{\mathrm{GS}}=0 \mathrm{~V}$ are shown in Fig. 7 for different values of $\mathrm{L}_{\mathrm{GD}}$. Note that horizontal axis scales are different for

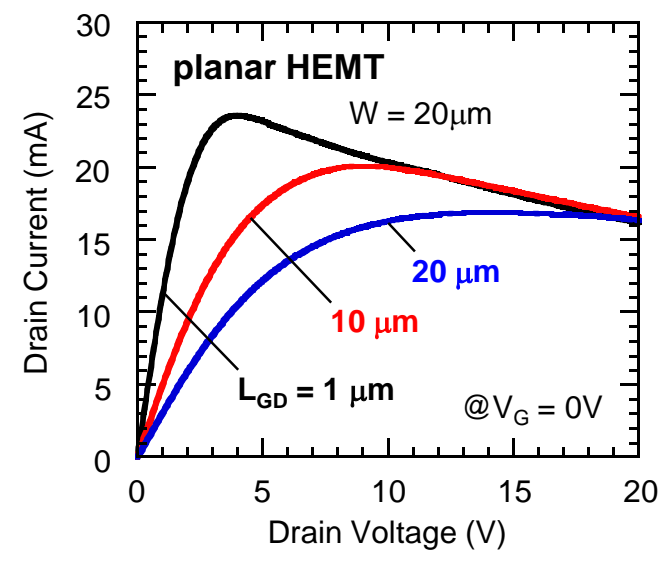

(a)

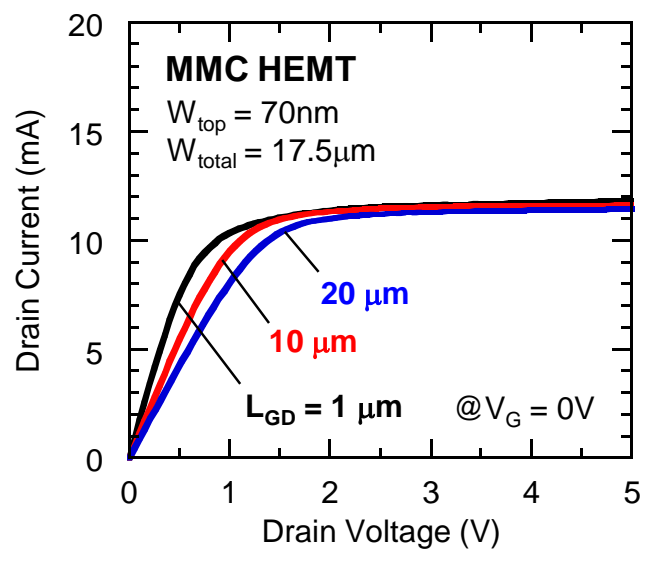

(b)

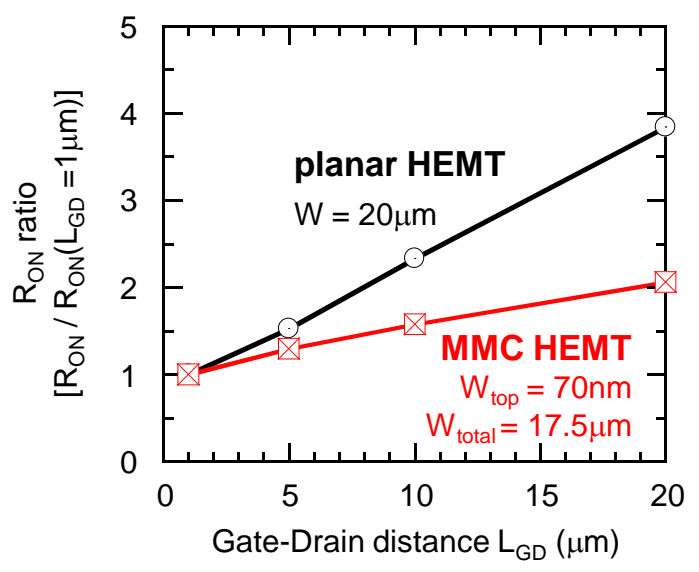

(c)

Fig. 7. $\mathrm{I}_{\mathrm{DS}}-\mathrm{V}_{\mathrm{DS}}$ characteristics at $\mathrm{V}_{\mathrm{G}}=0 \mathrm{~V}$ for different values of $\mathrm{L}_{\mathrm{GD}}$ of (a) planar and (b) MMC HEMTs, and (c) $\mathrm{R}_{\mathrm{ON}}$ values at any given $\mathrm{L}_{\mathrm{GD}}$ normalized to its value at $\mathrm{L}_{\mathrm{GD}}$ of $1 \mu \mathrm{m}$.

the two devices. The I-V curves of the planar HEMT showed pronounced $\mathrm{L}_{\mathrm{GD}}$ dependence as can be seen in Fig. 7(a). As the $\mathrm{L}_{\mathrm{GD}}$ increased, the $\mathrm{V}_{\text {knee }}$ increased and the I-V slope in the linear region decreased. This is typical in planar-type $\mathrm{AlGaN} / \mathrm{GaN}$ HEMTs $[35,36]$. The planar device also exhibited pronounced current decrease in the high drain bias region. Since the peak current density exceeded $1 \mathrm{~A} / \mathrm{mm}$, this is due to the self-heating effect in the channel. In fact, no reduction of the saturation 


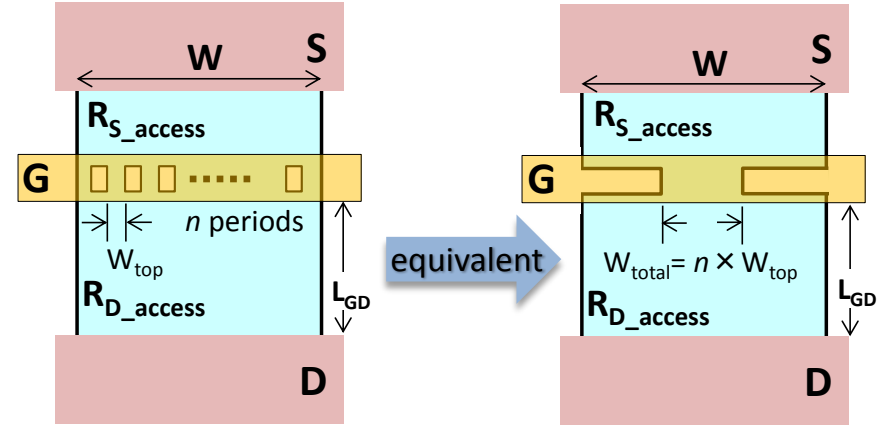

Fig. 8. The MMC device with $n$ periods of nano-channel each having a width of $\mathrm{W}_{\text {top }}$ and the equivalent single channel planar structure with a channel width of $\mathrm{W}_{\text {total }}=n \times \mathrm{W}_{\text {top }}$.

current was observed in pulsed I-V characteristics using a quiescent-bias condition of $\mathrm{V}_{\mathrm{DS} \_ \text {base }}=0 \mathrm{~V}$ and $\mathrm{V}_{\mathrm{G} \_ \text {base }}=0 \mathrm{~V}$.

On the other hand, as evident in Fig. 7(b), we observed small change in $\mathrm{V}_{\text {knee }}$ for the MMC HEMTs. Figure $7(\mathrm{c})$ shows the change in the on-resistance $\left(\mathrm{R}_{\mathrm{ON}}\right)$ at $\mathrm{V}_{\mathrm{G}}=0 \mathrm{~V}$, calculated from the I-V curves in the linear region, as a function of $\mathrm{L}_{\mathrm{GD}}$. The $\mathrm{R}_{\mathrm{ON}}$ values at any given $\mathrm{L}_{\mathrm{GD}}$ are normalized to its value at $\mathrm{L}_{\mathrm{GD}}$ of $1 \mu \mathrm{m}$. Both devices showed nearly linear relationship between $\mathrm{R}_{\mathrm{ON}}$ and $\mathrm{L}_{\mathrm{GD}}$, very similar to the data reported by Choi et al. [37] and Visalli et al. [38]. This is due to the increase in drain access resistance with $\mathrm{L}_{\mathrm{GD}}$. However, the MMC HEMT showed much weaker $\mathrm{R}_{\mathrm{ON}}$ dependence on $\mathrm{L}_{\mathrm{GD}}$.

Although a mechanism for this is still underlined, it can be understood that the relative access resistance of the MMC HEMT is smaller than that of the planar device. In the MMC HEMT, the device width (W) is $100 \mu \mathrm{m}$, while the effective channel width $\left(\mathrm{W}_{\text {total }}\right)$ is $17.5 \mu \mathrm{m}$. This suggests that the equivalent drain access resistance of the MMC device is about the same factor lower compared with that of the planar device, as schematically shown in Fig. 8. We then carried out calculations of the drain I-V curves for both devices with different $\mathrm{L}_{\mathrm{GD}}$ values, including the effect of drain and source access resistances. To avoid self-heating effect in the planar HEMT, as shown in Fig. 7(a), we compared the calculated results with the pulse-measured data under a quiescent-bias condition of $\mathrm{V}_{\mathrm{DS} \_ \text {base }}=0 \mathrm{~V}$ and $\mathrm{V}_{\mathrm{G}_{\text {_base }}}=0 \mathrm{~V}$. For the planar device, the measured $I_{D S}-V_{D S}$ curves and their variation with $\mathrm{L}_{\mathrm{GD}}$ shown in Fig. 7(a) are reasonably reproduced by the calculations. The calculated $\mathrm{R}_{\mathrm{ON}}$ values for MMC device are higher than the experimental data. This indicates that there are other factors affecting the observed insensitivity of the MMC device with $\mathrm{L}_{\mathrm{GD}}$ variation.

To investigate the operation stability of the MMC HEMT, we have performed off-stress-induced current collapse measurements. Initially, the drain I-V characteristics were measured. The devices were then subjected to off-state stress consisting of $\mathrm{V}_{\text {DS_stress }}$ ranging from $10 \mathrm{~V}$ to $50 \mathrm{~V}$ simultaneous with a $\mathrm{V}_{\mathrm{G}_{\text {_stress }}}$ of $-8 \mathrm{~V}$ applied for $10 \mathrm{~s}$. Immediately after removing the stress bias, the $I_{D S}-V_{D S}$ characteristics were again measured. In between each current collapse measurement, the device under test was exposed to UV light with wavelengths ranging from 250 to $400 \mathrm{~nm}$ to quickly recover the drain current from the current collapse.

The $\mathrm{I}_{\mathrm{DS}}-\mathrm{V}_{\mathrm{DS}}$ characteristics of the planar and MMC HEMTs

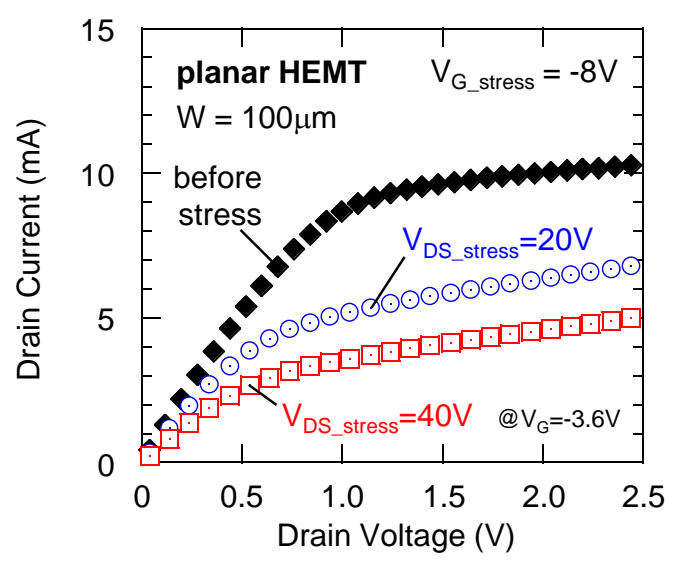

(a)

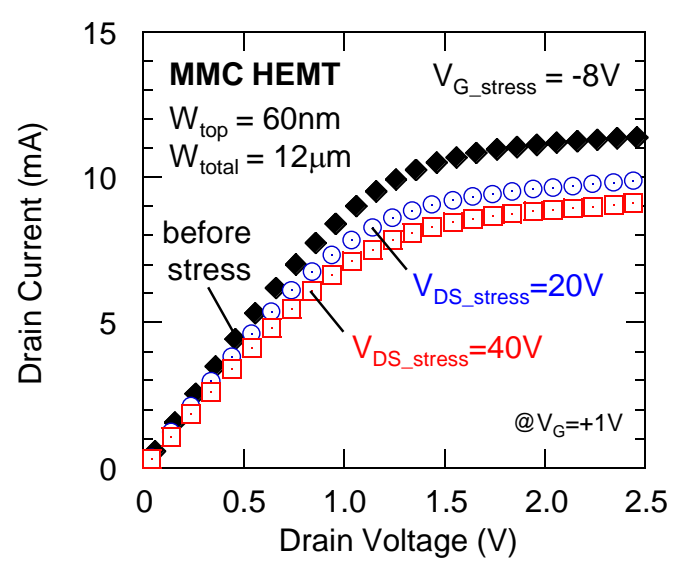

(b)

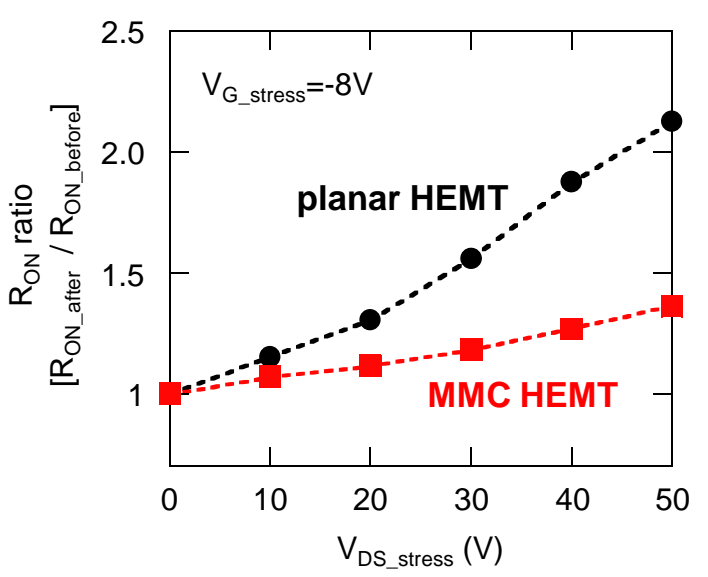

(c)

Fig. 9. Comparison of current collapse in (a) planar and (b) MMC HEMTs with $\mathrm{L}_{\mathrm{GD}}=10 \mu \mathrm{m}$. (c) Off-state stress induced change in $\mathrm{R}_{\mathrm{ON}}$ ratio (ratio of the on-resistance after stress to its value before stress) as a function of the applied $\mathrm{V}_{\mathrm{DS} \_ \text {stress. }}$

with $\mathrm{L}_{\mathrm{GD}}=10 \mu \mathrm{m}$ before and after the off-state stresses are shown Fig. 9. The gate drive voltages, $\mathrm{V}_{\mathrm{G}}=-3.6 \mathrm{~V}$ for the planar and $\mathrm{V}_{\mathrm{G}}=+1 \mathrm{~V}$ for the MMC HEMTs, were so chosen as to minimize the effect of self-heating and to compare the I-V characteristics at almost the same drain current level. For the planar HEMT, a significant decrease in drain current due to the off-state stress was observed. The current collapse becomes more pronounced with increasing the drain stress bias. On the 


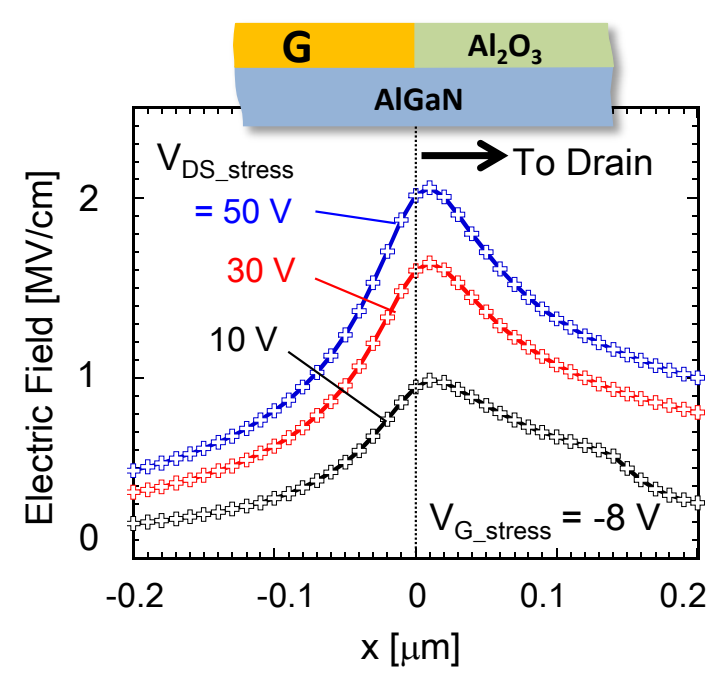

Fig. 10. Calculated electric field profiles along the 2DEG channel for different $\mathrm{V}_{\mathrm{DS} \_ \text {stress }}$ with $\mathrm{V}_{\mathrm{G}_{\text {_stress }}}$ kept constant at $-8 \mathrm{~V}$.

other hand, as shown in Fig. 9(b), the MMC HEMT exhibited a much weaker current collapse behavior even after the application of high drain stress bias.

Figure 9(c) shows the ratio of the $\mathrm{R}_{\mathrm{ON}}$ before and after the off-state stress as a function of the drain stress bias. For the conventional planar HEMT, $\mathrm{R}_{\mathrm{ON}}$ drastically increased with increasing drain stress bias. In case of unpassivated HEMTs, greater increase in $\mathrm{R}_{\mathrm{ON}}$ was observed in high drain stress range [29]. We have calculated electric field profile near the gate edge, and confirmed the peaking of the electric field at the gate edge of the drain side as shown in Fig. 10. The higher the $\mathrm{V}_{\mathrm{DS} \_ \text {stress}}$, the higher is the electric field peak, resulting in the more pronounced $\mathrm{R}_{\mathrm{ON}}$ increase, as shown in Fig.9(c). The given electric profile is valid for both devices because the gate electrode layout of the MMC HEMT is the same with that of the planar HEMT, i.e., the gate electrode edges are in contact with the entire width of the access regions. However, we observed less change in $\mathrm{R}_{\mathrm{ON}}$ for the MMC HEMT even after the application of high drain bias stress.

In addition to the DC current collapse characterization, we have also performed pulsed current I-V measurements under two quiescent-bias conditions, $\left(\mathrm{V}_{\mathrm{DS} \_ \text {base }}, \mathrm{V}_{\mathrm{G}_{-} \text {base }}\right)=\left(\begin{array}{lll}0 & \mathrm{~V}, 0 \mathrm{~V}\end{array}\right)$ and $\left(\mathrm{V}_{\text {DS_base, }}, \mathrm{V}_{\mathrm{G}_{-} \text {base }}\right)=(20 \mathrm{~V},-6 \mathrm{~V})$. The pulse width is $5 \mu \mathrm{s}$ while the pulse period is $500 \mu \mathrm{s}(1 \%$ duty cycle). As shown in Fig. 11, the planar HEMT showed pronounced current dispersion between the two quiescent bias points. On the other hand, smaller dispersion in the drain current was observed in the MMC device, indicating resistance to the off-stress-induced current collapse.

One of the possible mechanisms for the current collapse is the surface charging effect arising from electron trapping at surface states of AlGaN [20, 39-41]. The off-state stress can induce electron tunneling injection into the $\mathrm{AlGaN}$ surface from the gate edges, leading to accumulation of negative charges due to electron trapping. Consequently, a local depletion of the 2DEG density particularly at the gate edge of the drain side causes the increase in $\mathrm{R}_{\mathrm{ON}}$. This is similar to the $\mathrm{R}_{\mathrm{ON}}$ dependence on $\mathrm{L}_{\mathrm{GD}}$, as shown in Fig. 7. In addition, Fig.

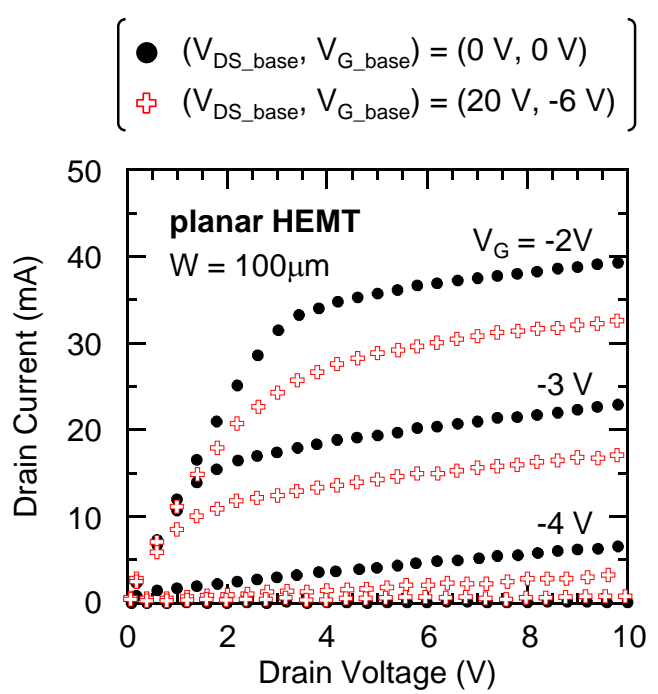

(a)

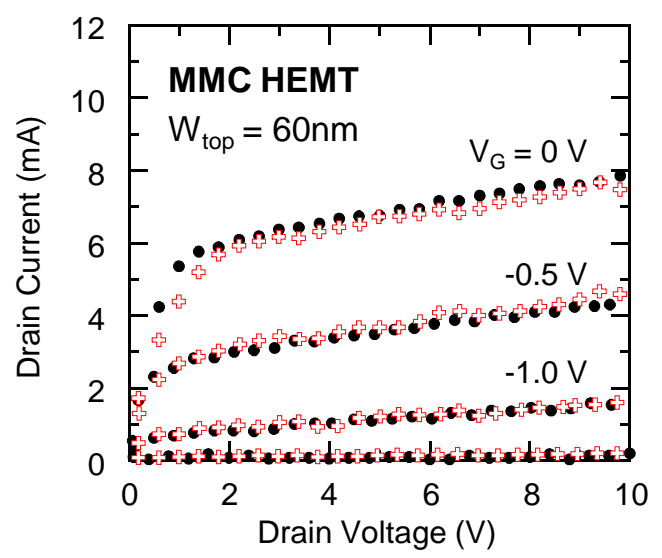

(b)

Fig. 11. Comparison of current dispersion between pulsed $I_{D S}-V_{D S}$ characteristics of planar and MMC HEMTs. The pulsed $I_{D S}-V_{D S}$ curves were obtained using two quiescent bias conditions: (1) $\mathrm{Q}_{1}=\left(\mathrm{V}_{\mathrm{DS} \_ \text {base}}\right.$, $\left.\mathrm{V}_{\mathrm{G}_{\_} \text {base }}\right)=(0 \mathrm{~V}, 0 \mathrm{~V})$ and $(2) \mathrm{Q}_{2}=\left(\mathrm{V}_{\mathrm{DS} \_ \text {base }}, \mathrm{V}_{\mathrm{G}_{-} \text {base }}\right)=(20 \mathrm{~V},-6 \mathrm{~V})$.

11(a) shows clear decrease of the saturation current under the stress bias condition. Tajima and Hashizume [41] recently carried out a unique characterization of current collapse using a dual-gate structure. When the gate-bias stress under the off state was applied to the additional gate between the main gate and the drain electrode, they observed a marked increase in $\mathrm{R}_{\mathrm{ON}}$ but no effect on the saturation current. On the other hand, the off-state stress on the main gate itself caused a decrease in drain saturation current as well as an increase in $\mathrm{R}_{\mathrm{ON}}$. These results indicated that the off-state gate stress induces "virtual gates" in the gate edges expanding in both the drain and source directions [41]. Thus the decrease of the saturation current under the stress bias condition shown in Fig. 11(a) is due to a surface trapping effect at the source-gate region.

Using a numerical fitting to the data of the planar device shown in Fig. 9(a), as described in [29], we estimated the change in the drain access resistance $\left(\Delta R_{D}\right)$ after the bias stress. In case of the drain stress bias of $50 \mathrm{~V}$, we obtained $\Delta R_{D}$ of 73 $\Omega$. This is much higher than the channel resistance of about 16 $\Omega$ for the planar HEMT operating at $\mathrm{V}_{\mathrm{G}}=-3.6 \mathrm{~V}$, leading to the 
marked current collapse after the stress. For the MMC device, the relative reduction of drain access resistance, as explained above, can weaken the increase in $\mathrm{R}_{\mathrm{ON}}$ even after applying similar stress bias. Indeed, simulation using the estimated $\Delta R_{D}$ of $73 \Omega$, showed more severe current collapse than the experimental result shown in Fig. 9(b). The resistance of each nano-channel for the MMC device is estimated to be about 5 $\mathrm{k} \Omega$ at $\mathrm{V}_{\mathrm{G}}=+1 \mathrm{~V}$. Thus, the channel resistance of the MMC HEMT is more than one order of magnitude higher than the increase in access resistance induced by the off-state stress. On the basis of the results shown in Figs. 7, 9, 11, it is likely that such high impedance of a nano-channel also contributes to the fact that the MMC HEMT is rather insensitive to changes in access resistance.

\section{CONCLUSION}

We have demonstrated the superior current stability of multi-mesa-channel (MMC) AlGaN/GaN HEMTs over the standard planar HEMTs. The MMC HEMT with unique parallel mesa structures under the gate electrode led to surrounding-field effect resulting in a shallower threshold voltage and a smaller subthreshold slope than those of the standard planar-type HEMT. Moreover, the MMC HEMT had a lower knee voltage and a weaker dependence of on-resistance on the gate-drain distance. Following identical off-state bias stress, the MMC HEMT exhibited significantly less increase in $\mathrm{R}_{\mathrm{ON}}$ compared with the planar HEMT. In the MMC HEMT, the total channel width (effective channel width) is smaller than the device width, resulting into a lower relative access resistance of the MMC HEMT compared with that of the planar device. This can reduce the effects of access resistance on the drain current. In addition, the resistance of nano-channel of the MMC structure is estimated to be more than one order of magnitude higher than the increase in access resistance induced by the off-state stress. It is likely that a high impedance of each nano-channel also contributes to current stability of the MMC HEMT.

\section{REFERENCES}

[1] H. Kambayashi, Y. Satoh, S. Ootomo, T. Kokawa, T. Nomura, S. Kato, and T. P. Chow, "Over 100 A operation normally-off AlGaN/GaN hybrid MOS-HFET on Si substrate with high-breakdown voltage," Solid-State Electron., vol. 54, no. 6, pp. 660-664, June 2010.

[2] M. Kanamura, T. Ohki, T. Kikkawa, K. Imanishi, T. Imada, A. Yamada, and N. Hara, "Enhancement-Mode GaN MIS-HEMTs with n-GaN/i-AlN/n-GaN Triple Cap Layer and High-k Gate Dielectrics," IEEE Electron Device Lett., vol. 31, no. 3, pp. 189-191, Mar. 2010.

[3] F. Medjdoub, J. Derluyn, K. Cheng, M. Leys, S. Degroote, D. Marcon, D. Visalli, M. Van Hove, M. Germain, and G. Borghs, "Low On-Resistance High-Breakdown Normally Off AlN/GaN/AlGaN DHFET on $\mathrm{Si}$ Substrate," IEEE Electron Device Lett., vol. 31, no. 2, pp. 111-113, Feb. 2010.

[4] H. Hahn, G. Lukens, N. Ketteniss, H. Kalisch, and A. Vescan, "Recessed-Gate Enhancement-Mode AlGaN/GaN Heterostructure Field-Effect Transistors on Si with Record DC Performance," Appl. Phys. Exp., vol. 4, pp. 114102-1-114102-3, Nov. 2011.

[5] R. Chu, A. Corrion, M. Chen, R. Li, D. Wong, D. Zehnder, B. Hughes, and K. Boutros, "1200-V Normally Off GaN-on-Si Field-Effect Transistors With Low Dynamic ON-Resistance," IEEE Electron Device Lett., vol. 32, no. 5, pp. 632-634, May 2011.
[6] A. Nakajima, Y. Sumida, M. H. Dhyani, H. Kawai, and E. M. S. Narayanan, "GaN-Based Super Heterojunction Field Effect Transistors Using the Polarization Junction Concept," IEEE Electron Device Lett., vol. 32, no. 4, pp. 542-544, Apr. 2011.

[7] N. Otsuka, S. Nagai, H. Ishida, Y. Uemoto, T. Ueda, T. Tanaka, and D. Ueda, "GaN Power Electron Devices," ECS Trans. Gallium Nitride Silicon Carbide Power Technol., vol. 41. no. 8, pp. 51-70, Oct. 2011.

[8] M. Van Hove, S. Boulay, S. R. Bahl, S. Stoffels, X. Kang, D. Wellekens, K. Geens, A. Delabie, and S. Decoutere, "CMOS Process-Compatible High-Power Low-Leakage AlGaN/GaN MISHEMT on Silicon," IEEE Electron Device Lett., vol. 33, no. 5, pp. 667-669, May 2012.

[9] H. S. Lee, D. Piedra, M. Sun, X. Gao, S. Guo, and T, Palacios, "3000-V 4.3-m $\Omega \cdot \mathrm{cm}^{2}$ InAlN/GaN MOSHEMTs With AlGaN Back Barrier," IEEE Electron Device Lett., vol. 33, no. 7, pp. 982-984, Jul. 2012.

[10] U. Singisetti, M. H. Wong, J. S. Speck, and U. K. Mishra, "Enhancement-Mode N-Polar GaN MOS-HFET With 5-nm GaN Channel, $510-\mathrm{mS} / \mathrm{mm} \mathrm{g}_{\mathrm{m}}$, and $0.66-\Omega \cdot \mathrm{mm} \mathrm{R}_{\mathrm{on}}$," IEEE Electron Device Lett., vol. 33, no. 1, pp. 26-28, Jan. 2012.

[11] T. Nanjo, A. Imai, Y. Suzuki, Y. Abe, T. Oishi, M. Suita, E. Yagyu, and Y. Tokuda, "AlGaN Channel HEMT With Extremely High Breakdown Voltage," IEEE Trans. Electron Devices, vol. 60, no. 3, pp. 1046-1053, Mar. 2013.

[12] W. Saito, M. Kuraguchi, Y. Takada, K. Tsuda, I. Omura, and T. Ogura, "High Breakdown Voltage Undoped AlGaN-GaN Power HEMT on Sapphire Substrate and Its Demonstration for DC-DC Converter Application," IEEE Trans. Electron Devices, vol. 51, no. 11, pp. 1913-1917, Nov. 2004.

[13] Y. Uemoto, T. Morita, A. Ikoshi, H. Umeda, H. Matsuo, J. Shimizu, M. Hikita, M. Yanagihara, T. Ueda, T. Tanaka, and D. Ueda, "GaN Monolithic Inverter IC Using Normally-off Gate Injection Transistors with Planar Isolation on Si Substrate," in IEEE IEDM Tech. Dig., Baltimore, USA, 2009, pp. 165-168.

[14] J. Das, J. Everts, J. Van Den Keybus, M. Van Hove, D. Visalli, P. Srivastava, D. Marcon, K. Cheng, M. Leys, S. Decoutere, J. Driesen, and G. Borghs, "A 96\% Efficient High-Frequency DC-DC Converter Using E-Mode GaN DHFETs on Si," IEEE Electron Device Lett., vol. 32, no. 10 , pp. 1370-1372, Oct. 2011.

[15] G. Meneghesso, G. Verzellesi, F. Danesin, F. Rampazzo, F. Zanon, A. Tazzoli, M. Meneghini, and E. Zanoni, "Reliability of GaN High-Electron-Mobility Transistors: State of the Art and Perspectives," IEEE Trans. Device Mater. Rel., vol. 8, no. 2, pp. 332-343, June 2008.

[16] J. A. del Alamo, and J. Joh, "GaN HEMT reliability," Microelectron. Reliab., vol. 49, no. 9-11, pp. 1200-1206, Sept.-Nov. 2009.

[17] G. Meneghesso, M. Meneghini, A. Tazzoli, N. Ronchi, A. Stocco, A. Chini, and E. Zanoni, "Reliability issues of Gallium Nitride High Electron Mobility Transistors," Int. J. Micro. Wireless Techno., vol. 2, no. 1, pp. 39-50, Feb. 2010.

[18] J. Joh and J. A. del Alamo, "A Current-Transient Methodology for Trap Analysis for GaN High Electron Mobility Transistors," IEEE Trans. Electron Devices, vol. 58, no. 1, pp. 132-140, Jan. 2011.

[19] M. A. Khan, M. S. Shur, Q. C. Chen, and J. N. Kuznia, "Current/voltage characteristics collapse in $\mathrm{AlGaN} / \mathrm{GaN}$ heterostructure insulated gate field effect transistors at high drain bias," Electron. Lett., vol. 30, no. 25, pp. 2175-2176, Dec. 1994.

[20] R. Vetury, N. Q. Zhang, S. Keller, and U. K. Mishra, "The Impact of Surface States on the DC and RF Characteristics of AlGaN/GaN HFETs," IEEE Trans. Electron Devices, vol. 48. no. 3, pp. 560-566, Mar. 2001.

[21] S. Arulkumaran, G. I. Ng, C. H. Lee, Z. H. Liu, K. Radhakrishnan, N. Dharmarasu, Z. Sun, "Study of current collapse by quiescent-bias-stresses in rf-plasma assisted MBE grown $\mathrm{AlGaN} / \mathrm{GaN}$ high-electron-mobility transistors," Solid-State Electron., vol. 54, no. 11, pp. 1430-1433, Nov. 2010.

[22] S. DasGupta, L. B. Biedermann, M. Sun, R. Kaplar, M. Marinella, K. R. Zavadil, S. Atcitty, and T. Palacios, "Role of barrier structure in current collapse of $\mathrm{AlGaN} / \mathrm{GaN}$ high electron mobility transistors," Appl. Phys. Lett., vol. 101, no. 24, pp. 243506-1-243506-4, Dec. 2012.

[23] S. Karmalkar and U. K. Mishra, "Enhancement of Breakdown Voltage in AlGaN/GaN High Electron Mobility Transistors Using a Field Plate," IEEE Trans. Electron Devices, vol. 48, no. 8, pp. 1515-1521, Aug. 2001.

[24] Y. Okamoto, Y. Ando, T. Nakayama, K. Hataya, H. Miyamoto, T. Inoue, M. Senda, K. Hirata, M. Kosaki, N. Shibata, and M. Kuzuhara, "High-Power Recessed-Gate AlGaN-GaN HFET With a Field-Modulating Plate," IEEE Trans. Electron Devices, vol. 51, no.12, pp. 2217-2222, Dec. 2004. 
[25] W. Saito, T. Nitta, Y. Kakiuchi, Y. Saito, K. Tsuda, I. Omura, and M. Yamaguchi, "Suppression of Dynamic On-Resistance Increase and Gate Charge Measurements in High-Voltage GaN-HEMTs With Optimized Field-Plate Structure," IEEE Trans. Electron Devices, vol. 54, no. 8, pp. 1825-1830, Aug. 2007.

[26] G. Xie, E. Xu, J. Lee, N. Hashemi, B. Zhang, F. Y. Fu, and W. T. Ng, "Breakdown-Voltage-Enhancement Technique for RF-Based AlGaN/GaN HEMTs With a Source-Connected Air-Bridge Field Plate,“ IEEE Electron Device Lett., vol. 33, no. 5, pp. 670-672, May 2012.

[27] Y. Ando, K. Ishikura, K. Yamanoguchi, K. Asano, and H. Takahashi, "Theoretical and Experimental Study of Inverse Piezoelectric Effect in AlGaN/GaN Field-Plated Heterostructure Field-Effect Transistors," IEEE Trans. Electron Devices, vol. 59, no. 12, pp. 3350-3356, Dec. 2012.

[28] K. Ohi and T. Hashizume, "Drain Current Stability and Controllability of Threshold Voltage and Subthreshold Current in a Multi-Mesa-Channel AlGan/GaN High Electron Mobility Transistor," Jpn. J. Appl. Phys., vol. 48, no. 8, pp. 081002-1-081002-5, Aug. 2009.

[29] K. Ohi and T. Hashizume, "Reduction of current collapse in multi-mesa-channel AlGaN/GaN HEMTs," Phys. Stat. Sol. C, vol.9, no.3-4, pp.898-902, 2012.

[30] S. Liu, Y. Cai, G. Gu, J. Wang, C. Zeng, W. Shi, Z. Feng, H. Qin, Z. Cheng, K. Chen, and B. Zhang, "Enhancement-Mode Operation of Nanochannel Array (NCA) AlGaN/GaN HEMTs," IEEE Electron Device Lett., vol. 33, no. 3, pp. 354-356, Mar. 2012.

[31] B. Lu, E. Matioli, and T. Palacios, "Tri-Gate Normally-Off GaN Power MISFET," IEEE Electron Device Lett., vol. 33, no. 3, pp. 360-362, Mar. 2012.

[32] Y. Hori, C. Mizue, and T. Hashizume, "Process Conditions for Improvement of Electrical Properties of $\mathrm{Al}_{2} \mathrm{O}_{3} / \mathrm{n}-\mathrm{GaN}$ Structures Prepared by Atomic Layer Deposition," Jpn. J. Appl. Phys., vol. 49, no. 8, pp. 080201-1-080201-3, Aug. 2010.

[33] C. Mizue, Y. Hori, M. Miczek, and T. Hashizume, "Capacitance-Voltage Characteristics of $\mathrm{Al}_{2} \mathrm{O}_{3} / \mathrm{AlGaN} / \mathrm{GaN}$ Structures and State Density Distribution at $\mathrm{Al}_{2} \mathrm{O}_{3} / \mathrm{AlGaN}$ Interface," Jpn. J. Appl. Phys., vol. 50, no. 2, pp. 021001-1-021001-7, Feb. 2011.

[34] W. Saito, Y. Takada, M. Kuraguchi, K. Tsuda, I. Omura, T. Ogura, and H. Ohashi, "High Breakdown Voltage AlGaN-GaN Power-HEMT Design and High Current Density Switching Behavior," IEEE Trans. Electron Devices, vol. 50, no. 12, pp. 2528-2531, Dec. 2003.

[35] J. Kuzmik, G. Pozzovivo, J. -F. Carlin, M. Gonschorek, E. Feltin, N. Grandjean, G. Strasser, D. Pogany, and E. Gornik, "Off-state breakdown in InAlN/AlN/GaN high electron mobility transistors," Phys. Stat. Sol. (C), vol. 6, no. S2, pp. S925-S928, Jun. 2009.

[36] J. G. Lee, H. J. Lee, H. Y. Cha, M. Lee, Y. Ryoo, K. S. Seo, and J. K. Mun, "Field Plated AlGaN/GaN-on-Si HEMTs for High Voltage Switching Applications," J. Korean Phys. Soc., vol. 59, no. 3, pp. 2297-2300, Sept. 2011.

[37] Y. C. Choi, M. Pophristic, B. Peres, M. G. Spencer and L. F. Eastman, "Fabrication and characterization of high breakdown voltage $\mathrm{AlGaN} / \mathrm{GaN}$ heterojunction field effect transistors on sapphire substrates," J. Vac. Sci. Technol. B, vol. 24, no. 6, pp. 2601-2605, Nov./Dec. 2006.

[38] D. Visalli, M. Van Hove, J. Derluyn, S. Degroote, M. Leys, K. Cheng, M. Germain, and G. Borghs, "AlGaN/GaN/AlGaN Double Heterostructures on Silicon Substrates for High Breakdown Voltage Field-Effect Transistors with low On-Resistance," Jpn. J. Appl. Phys., vol. 48, no. 4, pp. 04C101-1-04C101-4, Apr. 2009.

[39] T. Hashizume, S. Ootomo and H. Hasegawa, "Suppression of current collapse in insulated gate $\mathrm{AlGaN} / \mathrm{GaN}$ heterostructure field-effect transistors using ultrathin $\mathrm{Al}_{2} \mathrm{O}_{3}$ dielectric," Appl. Phys. Lett., vol. 83, no. 14, pp. 2952-2954, Oct. 2003.

[40] T. Hashizume, S. Ootomo, T. Inagaki and H. Hasegawa, "Surface passivation of $\mathrm{GaN}$ and GaN/AlGaN heterostructures by dielectric films and its application to insulated-gate heterostructure transistors," J. Vac. Sci. Technol. B, vol. 21, no. 4, pp. 1828-1838, Jul./Aug. 2003.

[41] M. Tajima and T. Hashizume, "Impact of Gate and Passivation Structures on Current Collapse of AlGaN/GaN High-Electron-Mobility Transistors under Off-State-Bias Stress,” Jpn. J. Appl. Phys., vol. 50, no. 6, pp. 061001-1-061001-7, June 2011.

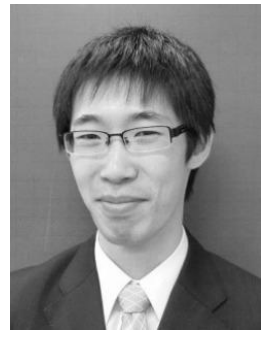

Kota Ohi received B.E., M.S. and Ph.D degrees in information science and technology from Hokkaido University, Hokkaido, Japan, in 2008, 2010, 2013, respectively. His research interests included GaN-based heterostructure transistors. In 2013, he joined Fuji Electric Corporation, Tokyo, Japan.

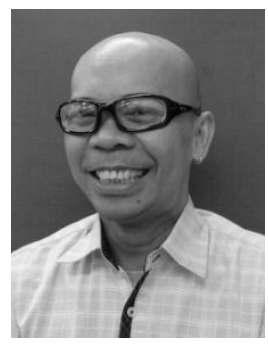

Joel T. Asubar received his M.S. and Ph.D. degrees from Nagaoka University of Technology, Niigata, Japan, in 2006 and 2009, respectively, working on molecular beam epitaxial growth of ferromagnetic semiconductors. In 2010, he joined the Research Center for Integrated Quantum Electronics of the Hokkaido University as a Post-doctoral fellow. Since 2006, he has authored or co-authored 20 papers in refereed international journals. His research interests include growth of semiconductor heterojunctions, fabrication, characterization and reliability studies of GaN-based transistors.

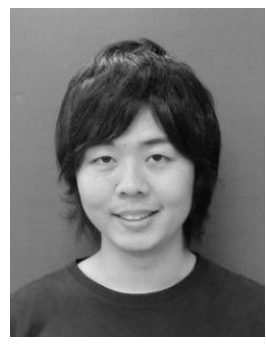

Kenya Nishiguchi received B.E. degrees in information science and technology from Hokkaido University, Hokkaido, Japan, in 2013. He is currently pursuing the M.S. degree in Hokkaido University, and his research interests include GaN-based heterostructure transistors.

Tamotsu Hashizume received B.E. and $\mathrm{Ph} . \mathrm{D}$ degrees in

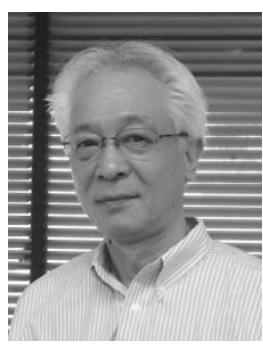
electrical engineering from Hokkaido University, Hokkaido, Japan, in 1981 and 1991, respectively. He became Research Associate of Kushiro National College of Technology in 1981. Then he moved to the Department of Electrical Engineering, Hokkaido Polytechnic College, as Lecturer, in 1987. In 1994, he moved to the Graduate School of Electronics and Information Engineering, Hokkaido University, as Associate Professor. Since 2004, he has been a Professor of Research Center for Integrated Quantum Electronics, Hokkaido University. His research interests included surface passivation and device processing technologies for III-V compound semiconductors. Currently, his major activity expanded into characterization and control of surfaces and interfaces of $\mathrm{GaN}$ and related materials and their application to GaN-based electron devices. He has authored or co-authored over 160 papers in scientific and technical journals. 